An interesting result of Landau's work is the proof of diamagnetism of the quantum electron gas. It was shown by Landau that in a transient state superconductors are composed of alternating common and superconducting regions.

As to the quantum theory of metals, Tamm and Blokhinzev have ascertained the role of image forces in the escape of electrons, and Tamm has discussed in detail the photo-effect from metals.

Many properties of ferromagnetic bodies have been accounted for by I. Akulov's anisotropy law. The quantum theory of ferromagnetic alloys, magnetostriction, etc., was developed by Vonsovsky (1940). The role of anharmonic effects in conductivity was discussed by A. Smirnov. A noteworthy place is occupied by Granovsky's and Vlasova's work on plasma.

Optics. Numerous detailed computations of spectra were carried out in the Leningrad Optical Institute by means of Fock's approximate methods. Much work was done on molecular spectra by Eliashevich and Stepanov. The modern theory of phosphorescence as a series of bimolecular reactions was developed by Blokhinzev (1937). Mandelstam and Leontovich extended the classical, and Tamm the quantum, theory of the Raman effect in solids. Leontovich studied the Rayleigh scattering in anisotropic fluids.

Among the ideas of Mandelstam's school mention may be made of an ingenious explanation by Tamm and Frank of the new kind of radiation, discovered by Cherenkov in Vavilov's laboratory, as due to electrons moving at a velocity exceeding the phase velocity of light in the given medium.

It is not possible to discuss, within the confines of the present article, various problems of classical electrodynamics and their technical application as pursued by Mandelstam and Papalexi with their associates Rytov, Filipov and others. Mention may, however, be made of the theory of non-linear vibrations, which has had some interesting practical implications (compare the monograph by Andrianov and Khaikin).

The above is a concise outline of the development of theoretical physics in the U.S.S.R. We may point with satisfaction to the existence of several scientific schools, and of a great number of young men of science who have already done valuable research. Work on theoretical physics carried out in the U.S.S.R. during the past twenty to twenty-five years has played a noteworthy part in modern developments of the subject.

\section{TERMINOLOGY IN THE GEOLOGICAL SCIENCES}

\section{By DR. R. H. RASTALL}

$\mathrm{F}$ OR many years past and especially of late in publications and conferences dealing with wartime problems and post-war planning, much stress has been laid on the unfortunate fact that in Great Britain the governing classes and the general public are not geologically minded. This is not the place to discuss in detail the disastrous neglect of economic and applied geology and mineralogy in some of the universities of Great Britain, but it is proposed rather to point out some ways in which the study and appreciation of geology by ordinary non-specialist educated people is rendered unnecessarily difficult.

One of the most glaring of these obstacles is by no means confined to geology, but is common to all biological sciences, namely, the volume and complication of the nomenclature now current. To the ordinary person, these sciences present themselves mainly as masses of outlandish and arbitrary names, which seem to have no sense or reason about them. Now there can be no doubt that of late years this has got much worse in geological studies, owing to the superabundance of minute detail now prevailing both in stratigraphy and palæontology. Fortunately, in petrology there has recently been a definite reaction against the multiplication of unnecessary names, although even this has not received all the support that might be wished.

By far the greater part of the trouble arises from the activities of the palæontologists. It is now a common saying and only too true that a field worker cannot name his own fossils: they all have to be sent to a specialist-a most unfortunate state of affairs, and a very unfair handicap on the fieldworker. It remains to consider what are the real causes of this situation. First of all, there is one inevitable reason: the extension of knowledge, against which nothing can be said. But the real crux is the way in which that extension of knowledge is employed. Now, unfortunately, the whole tendency has been and is to make things infinitely more complicated, instead of any attempt at simplification. It is commonly understood that modern palæontology is supposed to be founded on evolutionary lines, but it really seems that the present tendency to hairsplitting distinctions and infinite multiplication of new names is exactly contrary to the true principle of evolution. All the emphasis is on differences instead of resemblances : dividing instead of grouping. Many such distinctions correspond to extremely minute differences. Hence natural relationships are concealed, not emphasized. This is not the spirit of Darwin and Wallace.

In palæontology this tendency finds expression in the institution of new genera. In the case of new and hitherto undescribed fossils this is, of course, necessary, but the reference is here to the infinite sub-division of old and well-established genera. It is scarcely too much to say that almost no fossils known in the times of William Smith, Lyell, Buck. land, Sedgwick and Murchison still retain the same names, and it might almost be said of the era of Lapworth and Geikie. Such well-known names as Terebratula, Rhynchonella, Ostrea and Pecten have practically disappeared from the literature. The graptolites have probably suffered less than any other group in this way, probably because the authorities on this group happen to have been outdoor geologists. One such alteration in this group may perhaps be mentioned: the abandonment of the earlier name of Nemagraptus, which led too obviously to undergraduate attempts at humour (but I see no graptus).

The last sentence but one really touches the root of the matter. All these modern developments are mainly due to museum specialists; people with the Civil Service mind, who spend all their time indoors, surrounded by mountains of monographs instead of mountains of rocks, and appear to delight in making everything as complicated as possible. This is not evolutionary progress, but obscurantism, and if natural science in any form is ever to become a 
serious part of general education it will have to be amended.

Another factor, admittedly of less importance but still real, is the strict and indiscriminate application of the laws of priority, whereby old and universally known names are displaced by others discovered by antiquarian grubbing in forgotten publications. The motto here should be "let sleeping dogs lie", or "quieta non movere".

One result of all this is that an ordinary geologist who learnt his elementary work, say, forty or fifty years ago, when reading a modern stratigraphical paper often has a very vague idea of what it is all about, unless he happens to be a specialist in that particular subject. Sometimes the specific name may give him a clue to the identity of a fossil assigned to some genus of which he has never heard. Otherwise he may vainly hunt through much literature for an explanation.

This leads on naturally to another important side of the subject, namely, the effect of all this on the general view of geology taken by less specialized and especially by amateur readers; what may well be called the popular view. This can be simply summed up in a single phrase. Popular geology is being killed by pedantry, and even in schools and universities the subject is rendered so unattractive that few students select it. The falling off in the number of students of geology in many universities is notorious, but the special point to be made here is that this falling off is not the fault of the teachers, but of the state to which the science itself has been reduced by people who are not teachers, and moreover are not sufficiently men of the world to realize the disastrous effect on the science and its practical applications in the future of their well-meaning but wholly misdirected efforts.

Another instance may be mentioned as affecting what used to be a favourite field for amateurs, namely, the incessant introduction of new and uncouth names for minute sub-divisions of prehistoric cultures. This is usually considered to be part of geology, but it is really prehistoric archæology, and modern developments have made it quite unsuitable for inclusion in elementary teaching courses, owing to the multiplicity of detail. Students who take geology for any purpose beyond the mere attainment of a degree cannot afford to spend the necessary time on this kind of thing.

It is often said in academic circles that the study of parts of a scientific subject having no practical applications is an excellent preparation for something else later on; this sounds remarkably like the usual argument for a classical education. It is, of course, true that specialization can and often does begin too soon, but surely elementary education should be wide, not deep.

Another deterrent to the popularization of geology, so obvious as to make detailed discussion unnecessary, is the enormous number of zones and sub-zones now recognized in several systems; as, for example, the ammonites in the Jurassic and the graptolites in the Silurian. Furthermore, the names now applied to the ammonites in particular can only be described as appalling and quite sufficient in themselves to choke off any nascent interest in the subject, either in students or amateurs.

Finally, reference may be made to a complication for which there is an easy remedy. That is the practice of invariably quoting after the name of a fossil the authority by whom it was first described, even in supposedly popular or semi-popular writings. It is, of course, obvious that this must often be done in technical discussions by specialists, but it is submitted that it is entirely out of place in texts intended for students or amateurs. The effect on students is most depressing. They conclude that they are expected to learn three words for the name of every fossil, and also to remember the meaning of the abbreviation which often represents the name of the authority. Then there is the further complication of the brackets in which the name of the authority is often enclosed, which means that the said authority did not call the fossil by the name there printed, but something quite different. Incidentally, owing to a reason before discussed, nearly all names now have these brackets. The effect on amateurs is equally depressing.

Fortunately, petrology and mineralogy get on very well without such a system, although in point of fact in petrology there would probably be more excuse for it, since many rock-names have been used in varying senses; for example, the very common name dolerite. But it may well be considered what petrological literature would be like if one was com. pelled to write "basalt Pliny" or "granite God knows who" every time. For mineralogy the imagination reels at the prospect. Cannot palæontologists be induced to compare their own proceedings with this ?

The state of affairs here sketched must obviously be a passing phase, and there should eventually be found some means of simplification. If not, as a result of forty years experience of geology in all its branches, especially in teaching, it can only be said that the prospect is dark indeed.

\section{FREEDOM IN SCIENCE}

\section{BY DR. H. LOWERY}

$\mathbf{W}^{\mathrm{s}}$ AR-TIME necessity has required that science shall be planned in its applications to the prob. lems of national defence, food production, and other matters connected therewith. Indeed, the success or failure of a nation at war is easily seen to depend mainly upon how well it is able to utilize its scientific knowledge.

We must be careful, however, to distinguish between science on one hand and the applications of science on the other, a distinction that may be represented by the difference between science and technology. Science is concerned with the disinterested and dispassionate search for truth, and the man of science at work cannot see whither the road he travels will lead him. He must on occasion be prepared to follow what looks like a by-path, and it is vitally important that he should be free to do so if he chooses to leave his main road. A characteristic feature of technology, however, is that it is concerned with more or less clearly defined ends; the technologist sets out to achieve a definite object, improving a manufacturing process, carrying out to its logical conclusion some practical possibilities inherent in some general scientific principle, as, for example, when he sets out to design an electric motor for a particular purpose. While it is true that the technologist in his endeavour to achieve his goal may discover interesting new facts and may actually follow 